\title{
LOWER NEPHRON NEPHROSIS AFTER TRANSURETHRAL RESECTION OF THE PROSTATE
}

BY

\author{
JOHN SWINNEY AND B. E. TOMLINSON \\ From the Departments of Urology and Pathology, Newcastle General Hospital
}

(RECEIVED FOR PUBLICATION MAY 28, 1952)

Oliguria and anuria due to lower nephron nephrosis may occur after crushing injuries (Bywaters and Dible, 1942), incompatible blood transfusion (Baker and Dodds, 1925; Foy, Altmann, Barnes, and Kondi, 1943), burns (Goodpastor, Levenson, Tagnon, Lund, and Taylor, 1946), sulphonamide therapy (Hellwig and Reed, 1942; Lederer and Rosenblatt, 1942), septic abortion (Bratton, 1941), concealed accidental haemorrhage (Young, 1942), and occasionally after operations, particularly the operation of transurethral prostatic resection. In the past three years we have observed six cases, which have followed prostatic resection out of a total of 742 such operations.

Creevy (1947) showed that when water is used as the irrigating fluid during prostatic resection, haemoglobinaemia occurs, due to absorption through the prostatic veins of lysed blood and water itself. Haemoglobinaemia occurs in many cases without oliguria (Creevy, 1948; Biorn and Greene, 1949), and its degree bears no relationship to the severity of the renal failure. Whilst a number of isotonic solutions have been employed as irrigating fluids in prostatic resection (Ebert, 1949; Nesbit and Glickman, 1948; Garske, Phares, and Sweetser, 1949) we have used isotonic glucose solution, which does not cause haemoglobinaemia.

We have found that the oliguric syndrome has not been eliminated by the use of solutions which avoid haemoglobinaemia, as has been asserted (Chapman and Sutherland, 1952). Further, in some of our cases, transfusion, sulphonamide therapy, and clinical shock played no part, though these factors have been present in many reported cases of lower nephron nephrosis, and in most of those associated with transurethral prostatectomy.

Our six cases all developed oliguria or anuria. Water irrigation was employed in Cases 1 and 2; $5 \%$ glucose in Cases 3 to 6 (though in Case 3, for technical reasons, water was substituted for glucose during the operation). Their clinical and pathological findings are briefly described.

\section{Case Reports}

Case 1.-J.N., aged 70 years, had benign prostatic obstruction, for which prostatic resection was performed on November 10, 1949, when $25 \mathrm{~g}$. of prostatic tissue were resected. He had oliguria the following day, and was completely anuric for 73 hours until his death in uraemic coma on November 16.

Necropsy was performed 36 hours after death.

In addition to the renal lesion, there was extensive bilateral bronchopneumonia, confluent in both lower lobes. The kidneys together weighed $350 \mathrm{~g}$. They showed considerable scarring, and on bisection appeared to consist almost entirely of pale, swollen, cortical tissue, which bulged over the capsule.

Histology.-The glomeruli showed no abnormality. The cells of the first convoluted tubules were flattened and the lumen of the tubules wide. No necrosis was present. A few small areas of complete tubular degeneration were found in the outer medulla, the cells of the

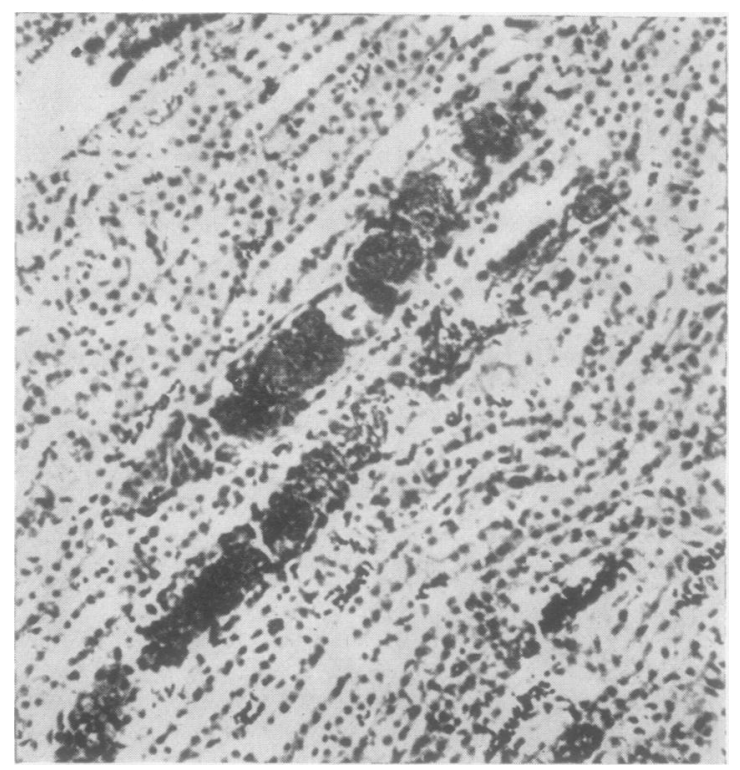

FIG. 1.-Granular casts in collecting tubules in Case 1. Haematoxylin and eosin, $\times 100$. 
tubules having disintegrated into a uniform granular material. Some polymorphic infiltration was seen in the interstitial tissue around these areas of necrosis.

Many of the second convoluted tubules contained copper-coloured, granular casts. Some of the tubules containing these casts showed no obvious abnormality of their lining cells. Others had grossly abnormal lining cells which were swollen and darkly staining. An occasional cast was scantily infiltrated with polymorphs.

There were very many pigmented, granular casts (copper-coloured in haematoxylin-and-eosin-stained sections) in the collecting tubules (Fig. 1); the interstitial tissue around some of these tubules was scantily infiltrated with polymorphs and lymphocytes, but the cells of the collecting tubules appeared normal. A few small foci of cellular infiltration were present around tubules not containing casts, and lymphocytic foci were present in the walls of some interlobular veins.

These findings are characteristic of lower nephron nephrosis. In the description of the subsequent cases only points of difference from the above are described fully.

Case 2.-A.G.M., aged 61 years, had benign prostatic obstruction, for which transurethral resection was performed on January 4, 1950, when $15 \mathrm{~g}$. of prostatic tissue were resected.

Oliguria was present, with a progressive rise of blood urea to $192 \mathrm{mg}$. \% on January 14 when diuresis occurred, and the blood urea had reverted to normal by January 19. The patient developed bronchopneumonia and died on January 20.

Necropsy was performed 48 hours after death.

In this man death was largely due to a severe upper respiratory infection and early bilateral bronchopneumonia.

The left kidney appeared normal; the right was pale and swollen, but showed no other gross abnormality.

Histology.-The right kidney showed severe early pyelonephritis. The left kidney, though macroscopically normal, showed the following histological lesions. Some collecting tubules contained brown, granular pigment, particularly prominent in the large tubules near the apex of the pyramid. One cast was infiltrated with polymorphs. In the outermost medullary zone were numerous, circumscribed, small collections of chronic inflammatory cells, in and around small segments of tubules. These cells were mostly plasma cells and lymphocytes with an occasional eosinophil and polymorph, and a small number of fibroblasts. Fragments of cast material were present in a few tubules in this area. Similar cellular collections were present in the immediate vicinity of a few glomeruli, particularly in the inner cortical zone. One large recent thrombus was present in a thin-walled vein in this zone.

Unfortunately the histology of the first convoluted tubules was obscured by severe post-mortem degeneration.

These lesions apparently represent the healing phase. This man had been oliguric for 10 days, but recovered clinically from the uraemia which followed the operation.

Case 3.-J.H., aged 87 years, had a carcinomatous prostatic obstruction with retention. He was grossly anaemic and this was treated initially. Transurethral resection was performed on December 15, 1950, $5 \mathrm{~g}$. of prostatic tissue being resected. He immediately became anuric, and died on December 21 in uraemic coma.

Necropsy was performed eight hours after death.

Outside the renal tract the only abnormalities were the presence of numerous small pigment stones in the gall-bladder and a severe zonal fatty change in the liver.

The kidneys together weighed $180 \mathrm{~g}$., and showed the gross appearances of severe atherosclerosis.

Histology.-The first convoluted tubules were dilated and contained a little albuminous material, and the cells showed considerable vacuolation of the cytoplasm, but the nuclei were well preserved. In a few collecting tubules and in a small number of second convoluted tubules in the cortex there was very scanty granular red pigment. Some extratubular pigment closely resembling the more usual intratubular material lay in the interstitial tissues of the medulla. Small foci of necrotic second convoluted tubules were present in the cortex, and necrotic loops of Henle in the outer medulla.

Case 4.-J.M., aged 71 years, had benign prostatic obstruction with acute retention.' Transurethral resection of $20 \mathrm{~g}$. of tissue was performed on January 26, 1951. Thereafter the patient was oliguric for 48 hours, and then completely anuric until his death in uraemic coma on February 6.

Necropsy was performed one and a half hours after death.

Apart from the kidneys, the only abnormality found was an enlarged heart with an old posterior infarction. The kidneys together weighed $440 \mathrm{~g}$., and showed marked foetal lobulation. The cortex was thickened, averaging $10-11 \mathrm{~mm}$. and in some places $15 \mathrm{~mm}$. across.

The medulla was pale except for a $1 \mathrm{~mm}$. thick, congested line at the cortico-medullary margin.

Histology.-The first convoluted tubules were well preserved but were very dilated. Some pink, rather solidlooking debris was present in the second convoluted tubules and loops of Henle in the cortex. In the cortex small vascular and cellular scars surrounded the distorted and regenerating second convoluted tubules.

The outer area of the medulla showed the most marked abnormality. Here, corresponding to the anatomical position of the loops of Henle, numerous tubules contained giant and distorted, deeply staining cells, the interstitial tissue being oedematous and scantily infiltrated with chronic inflammatory cells. The majority of the tubules in this zone showed marked evidence of cellular regeneration (Figs. 2 and 3).

Case 5.-C.B., aged 78 years, had a carcinomatous prostatic obstruction. On June 15, 1951, $5 \mathrm{~g}$. of prostatic tissue were resected, after which anuria developed and the patient died in uraemic coma on June 20 .

Necropsy was performed six hours after death, but permission for a general necropsy was refused. 


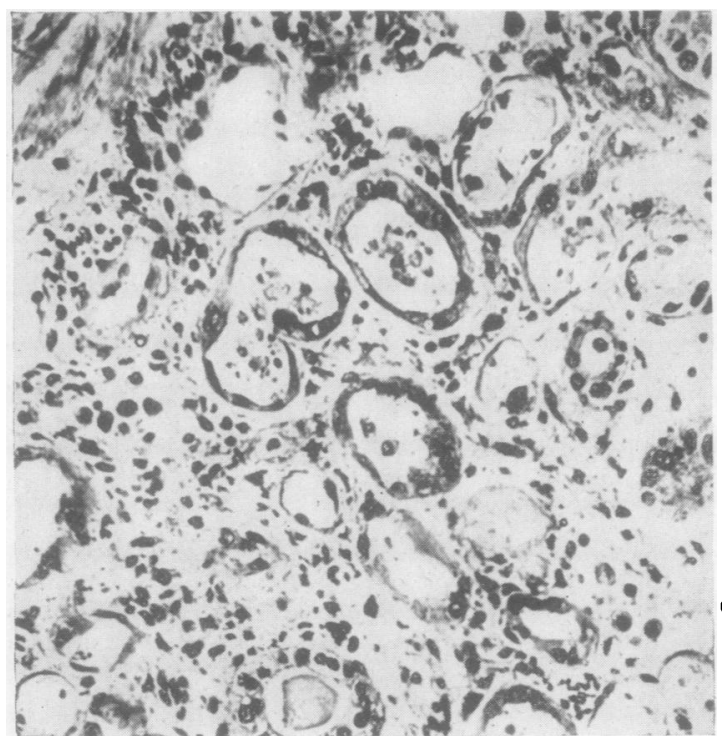

Fig. 2.-Cellular regeneration in the tubules in Case 4. Haematoxylin and eosin, $\times 160$

There were numerous small areas of acute infection in one kidney and a few similar areas in the other.

There were many pigmented casts in the second convoluted tubules, collecting tubules, and in some loops of Henle.

Only one small focus of necrotic tubules in the juxtamedullary zone was seen. There were several cortical foci of necrotic and regenerating tubules near the glomeruli with and without cast material. Two bluestaining casts (in haematoxylin-and-eosin-stained preparations) surrounded by giant cells were seen.

One unusual feature was the presence of intratubular red cells, sometimes associated with cast material, in the loops of Henle, in two glomerular spaces, and in immediately adjacent proximal convoluted tubules. The number of red cells in some of the lower tubules was suggestive of direct bleeding into these tubules rather than of the passage of blood from the glomerular space. Even a small quantity of blood in the glomerular space makes one reluctant to accept tubulo-venous anastomosis as the origin of the intratubular blood, as we did not find tubulo-venous anastomosis in any of the kidneys examined. The intratubular bleeding in this case was probably not directly associated with the lower nephron nephrosis.

Case 6.-J.C., aged 65 years, had a benign prostatic obstruction.

On August 1, 1951, $19 \mathrm{~g}$. of prostate were resected, and a transfusion of two pints of blood given. On August 4 oliguria began, and on August 8 he was anuric, and died in coma on August 9.

Necropsy was performed 22 hours after death.

Macroscopically the liver showed gross fatty change. There was a severe, haemorrhagic inflammation of the

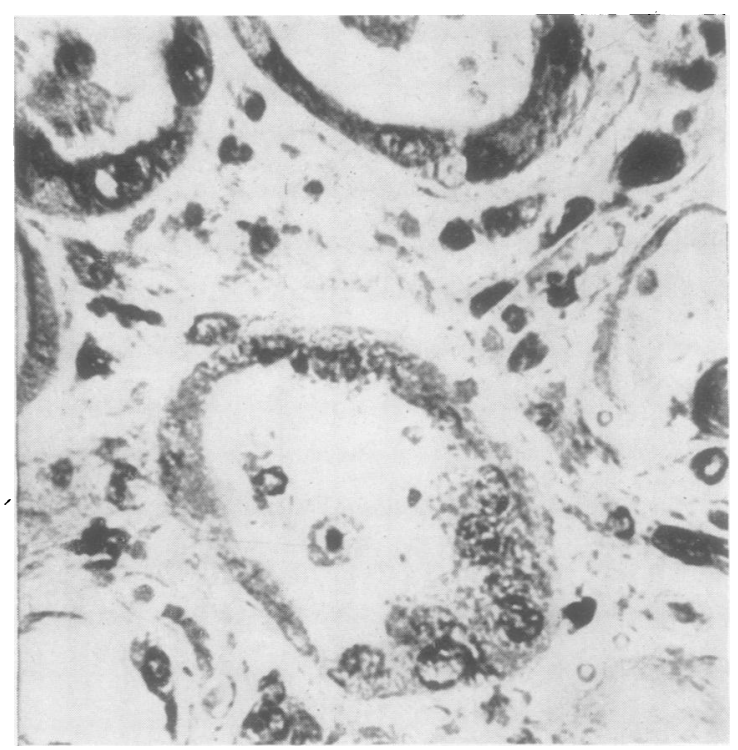

FIG. 3.-Cellular regeneration in the tubules in Case 4. Haematoxylin and eosin, $\times 560$.

pelvic peritoneal tissues as high as the lower abdominal wall anteriorly and the mid-lumbar vertebrae posterorily. No actual pus was found.

Kidney tisste was obtained within five hours of death. The kidneys together weighed 290 g., their only visible abnormality being pallor and some swelling of the cortex, which was $10 \mathrm{~mm}$. thick in some places.

Histological examination confirmed the severe fatty infiltration of the liver.

There was some swelling of the cells of the proximal convoluted tubules, congestion of the glomeruli, and

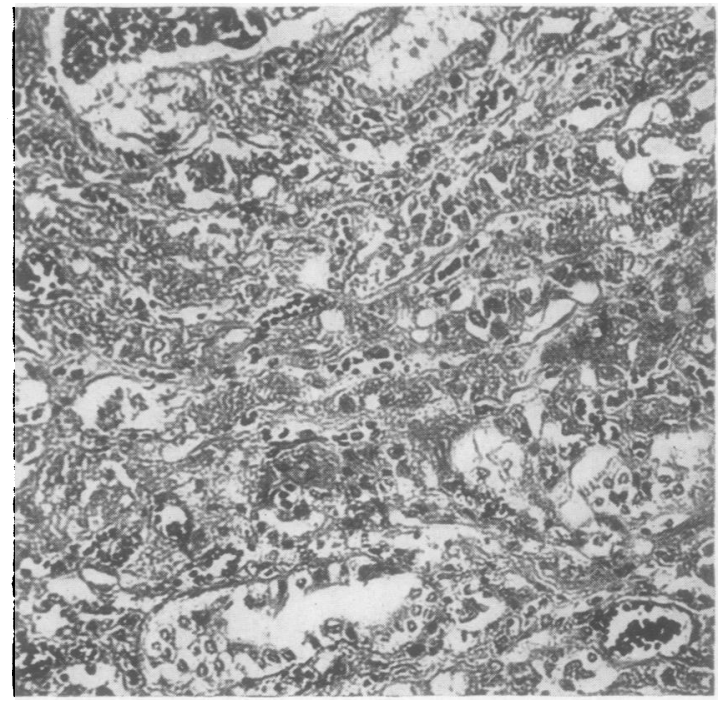

FIG. 4.-Necrotic tubules in Case 6. Haematoxylin and eosin, $\times 100$. 
small foci of necrotic second convoluted tubules in the cortex.

Many entirely necrotic tubules were present in the outer medulla, corresponding to the anatomical position of the loops of Henle. In many tubules no cells were seen, only granular debris within an ill-defined basement membrane remaining (Fig. 4). In a few tubules some large regenerating cells, showing mitosis, were present. Some necrotic areas, and the walls of a few large veins, showed scanty polymorphic infiltration.

Pigmented casts were not found in these kidneys.

\section{Discussion}

Similar lesions to those we have described have been seen in many clinical conditions. Bywaters and Dible (1942) gave prominence to the lesion in describing the anuria which may follow crushing injuries. The largest group of cases described, battle casualties, is that of Lucké (1946), and he and Mallory (1947) emphasized the variation in the amount of tubular damage and cast formation. The most marked change is in the distal tubules, notably the ascending limb of Henle's loop and the second convoluted tubule.

Changes in the proximal convoluted tubules have been described by many authors: for example, distension (Baker and Dodds, 1925), tubular degeneration (Hellwig and Reed, 1942; Lederer and Rosenblatt, 1942), and pigment cast formation (McLaughlin, Holyoke, and Bowler, 1947). Bell (1950) believes that hydropic degeneration of the proximal tubules is the essential lesion. Changes in these tubules were present in three of our cases, but in no case did we see actual necrosis, and we agree with Ayer and Gauld (1942) that it is "impossible to attach any great significance to any of these changes."

As stated above, there may be great variation in the degree of damage to the lower nephron, and although it sometimes appears insufficient to account for the loss of renal function, in some instances the damage certainly is sufficient. In Case 6 the necrosis involved a band of tubules in the outer medulla so severely that all the ascending limbs of the loops of Henle were destroyed. In Case 4 a similar extensive zone of grossly abnormal regenerating tubules was seen. In the other cases the areas of necrosis in the loops of Henle and second convoluted tubule were patchy and focal in distribution. It seems, therefore, that the name "lower nephron nephrosis" adequately emphasizes the anatomical location of a lesion which can nearly always be demonstrated.

Casts of a hyaline and granular type are often found in this condition, and their typical distribution is in the distal tubules. They provide an easily recognizable feature, and when present should at once direct the attention of the histologist to the condition of the cells in the lower tubules, particularly in the outer medulla. If the clinical history suggests the possibility of lower nephron damage, search for it is automatic. In the absence of suggestive history, the necrotic lesions, particularly if they are scanty or focal, and if pigmented casts are absent or few, may well be overlooked (Creevy, 1948). The longer post-mortem examination is delayed, the more likely is the lesion to be overlooked. Advanced post-mortem change may make it impossible to determine whether or not antemortem necrosis was present, and in the absence of typical casts it may not be possible to reach a diagnosis. Further, organs which show severe post-mortem change tend to receive less careful attention from pathologists. We feel, therefore, that this lesion may be more common than is suggested by the literature or standard text-books.

In the British literature no account has been published of lower nephron nephrosis complicating prostatectomy, though Wardill (1946) was probably the first to observe its occurrence. We know of no case in which the lesion was found after an open prostatectomy, and its occurrence after transurethral resection may be due to some factor in the operative technique in that procedure.

In prostatic operations, blood loss (and possible transfusion), anaesthesia, and surgical shock are factors common to all. Further, the lesion occurs in the absence of recognizable surgical shock and without transfusion. When oliguria follows transfusion, the possibility that the transfusion was incompatible should always be considered. In only one case in this series was a transfusion given, and there was nothing to suggest that this was incompatible. There was no prolonged fall of blood pressure in any of the cases.

An important difference between transurethral resection and all the other forms of prostatectomy is that in the former the bladder is filled and emptied continuously throughout the operation. The irrigating fluid, be it water, $5 \%$ glucose, glycine solution, or mannitol, is absorbed from the bladder into the blood stream through the prostatic veins (Creevy, 1948; Bunge and Barer, 1948). There is convincing evidence that prostatic fluid enters the blood stream during operation. The piecemeal cutting of the prostate releases secretion, and some of this, along with the irrigating fluid, enters the circulation through the open wound at the operation site.

Post-operative Rise in the Serum Acid Phosphatase.-A high concentration of phosphatase is present in the effluent from the bladder during the 
operation. In one case, after the resection of only $2 \mathrm{~g}$. of tissue, the effluent contained 1,600 units of formalin-stable acid phosphatase per $100 \mathrm{ml}$. Absorption into the blood stream also occurs, as a small but definite rise in the serum acid phosphatase is found in almost every case following resection, and often the rise is dramatic. The greatest rises follow large rasections, but the rise is not always proportional to the amount of tissue removed. This is not surprising, since the rise must depend on two factors, apart from the amount of tissue resected. These are the amount of phosphatase actually present in the tissue removed, and the amount of irrigating fluid which enters the blood stream. The former varies considerably, since the amount of acinar and fibro-muscular tissue in the hypertrophied prostate varies greatly, and the latter depends on the length of the operation, the fluid pressure in the bladder, and the number and size of the opened vascular channels.

TABLE

Serum ACid Phosphatase LeVels* immediately Before and AFTER OPERATION

\begin{tabular}{|c|c|c|}
\hline \multirow{2}{*}{$\begin{array}{l}\text { Prostatic Tissue } \\
\text { Removed (g.) }\end{array}$} & \multicolumn{2}{|c|}{$\begin{array}{l}\text { Serum Acid Phosphatase } \\
\text { (units per } 100 \mathrm{ml} \text {.) }\end{array}$} \\
\hline & Before Operation & After Operation \\
\hline $\begin{array}{c}\text { Transurethral prost } \\
4 \\
4 \\
4 \\
6 \\
6 \\
14 \\
15 \\
17 \\
18 \\
20 \\
23 \\
25 \\
45 \\
49\end{array}$ & $\begin{array}{c}\text { tresection) } \\
0.75 \\
2.25 \\
2 \cdot 0 \\
2 \cdot 7 \\
2 \cdot 4 \\
2.3 \\
1 \cdot 5 \\
1 \cdot 0 \\
1.1 \\
2.7 \\
2 \cdot 1 \\
1.4 \\
3 \cdot 5 \\
1.2\end{array}$ & $\begin{array}{r}3 \cdot 0 \\
3 \cdot 4 \\
19 \cdot 8 \\
2 \cdot 7 \\
7 \cdot 9 \\
30 \cdot 0 \\
6 \cdot 4 \\
34 \cdot 0 \\
19 \cdot 2 \\
41 \cdot 8 \\
53 \cdot 5 \\
12 \cdot 5 \\
86.0 \\
39 \cdot 2\end{array}$ \\
\hline $\begin{array}{c}\text { Open prostatectomy } \\
40 \\
43 \\
52 \\
90\end{array}$ & 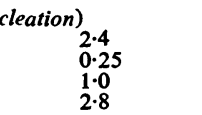 & $\begin{array}{l}2 \cdot 7 \\
0 \cdot 8 \\
5 \cdot 1 \\
4 \cdot 2\end{array}$ \\
\hline
\end{tabular}

*Formaldehyde stable-Abul-Fadl and King, 1948.

The accompanying table shows that the rise in phosphatase level is small with small resections, but when over $10 \mathrm{~g}$. tissue are removed the rise is usually great. That this rise is due to the method of removal rather than mere manipulation of the prostate is shown by comparing these results with the phosphatase levels following prostatic enucleation. In the latter, despite the large glands removed, the rise was extremely small, being of the same order as, or less than, that resulting from the removal of onetenth to one-twentieth of the tissue by resection.

The fall to normal takes 24-36 hours, being longer when the post-operative rise is great. In the largest rise recorded (to 86 units) the phosphatase was 17 units seven hours after operation, and 2.5 units 31 hours after. When the post-operative level was 39.2 units, the level four hours and 24 hours postoperatively was 9.3 and 4.5 units respectively. When the post-operative level was 12.8 units, it had dropped to 0.75 units after 24 hours.

Clearly routine acid phosphatase levels should not be measured for 24 hours after enucleation and not for two days after the operation of resection. We have not ascertained whether prostatic massage or digital examination of the prostate per rectum influences the serum level.

We have also been unable to demonstrate any relationship between the rise in serum acid phosphatase, which indicates absorption of prostatic secretion into the blood stream, and the occurrence of tubular necrosis, and work is proceeding to investigate this further.

\section{Summary}

Six cases of lower nephron nephrosis following transurethral resection of the prostate are described; isotonic solutions as irrigating fluids have not eliminated this risk.

Lower nephron nephrosis does not occur after open prostatectomy.

Absorption of prostatic secretion from the bladder during resection is shown by the dramatic rise of serum acid phosphatase; during enucleation of the prostate a very small rise of phosphatase is observed. We have no evidence that the renal lesion is related to the absorption of secretion.

We would like to thank Dr. R. P. Smith and Dr. J. Hait-Mercer for their help and advice, and Mr. A. Hall for the photomicrographs.

\section{REFERENCES}

Abul-Fadl, M. A. M., and King, E. J. (1948). J. Path. Bact., 60, 149. Ayer, G. D., and Gauld, A. G. (1942). Arch. Path., Chicago, 33, 513. Baker, S. L., and Dodds, E. C. (1925). Brit. J. exp. Path, 6, 247. Bell, E. T. (1950). Renal Diseases, 2nd ed. London.

Biorn, C. L., and Greene, L. F. (1949). Surg. Gynec. Obstet., 88, 389. Bratton, A. B. (1941). Lancet, 1, 345.

Bunge, R. G., and Barer, A. P. (1948). J. Urol., Baltimore, 60, 122. Bunge, R. G., and Barer, A. P. (1948). J. Urol., Baltimore, 60, 122 Chapman, T. L., and Sutherland, J. W. (1952). Brit. med. J., 1, 72. Creevy, C. D. (1947). J. Urol., Baltimore, 58, 125.

(1948). Ibid., 59,1217

Ebert, C. E. (1949). lbid., 62, 736.

Foy, H., Altmann, A., Barnes, H. D., and Kondi, A. (1943). Trans. roy. Soc. trop. Med. Hyg., 36, 197.

Garske, G. L., Phares, O. C., and Sweetser, T. H. (1949). J. Urol., Baltimore, 62, 322.

Goodpastor, W. E., Levenson, S. M., Tagnon, H. J., Lund, C. C., and Taylor, F. H. L. (1946). Surg. Gynec. Obstet., 82, 652.

Hellwig, C. A., and Reed, H. L. (1942). J. Amer. med. Ass., 119, 561. Lederer, M., and Rosenblatt, P. (1942). Ibid., 119, 8.

Lucké, B. (1946). Milit. Surg., 98, 371.

Mallory, T. B. (1947). Amer. J. clin. Path., 17, 427.

McLaughlin, W. L., Holyoke, J. B., and Bowler, J. P. (1947). J. Urol., Baltimore, $58,47$.

Nesbit, R. M., and Glickman, S. I. (1948). Ibid., 59, 1212.

Wardill, W. E. M. (1946). Brit. J. Urol., 18, 72.

Young, J. (1942). Brit. med. J., 2, 715 . 